\title{
灵国pubvet
}

https://doi.org/10.31533/pubvet.v15n10a932.1-9

\section{Mycoplasma hyopneumoniae em suínos: Revisão}

\author{
Bruna Araújo Euzébio Alves Jacob Lopes ${ }^{1^{*} \bullet}$, Danilsy Córnelio Pereira ${ }^{1} \bullet$, Darlyson da Silva \\ Figueiredo $^{1 \oplus}$, Magna Coroa Lima ${ }^{2} \odot$
}

${ }^{1}$ Graduanda em Medicina Veterinária - Centro Universitário de Viçosa, Viçosa-MG.

${ }^{2}$ Docente em Medicina Veterinária - Centro Universitário de Viçosa, Viçosa-MG.

*Autor para correspondência, E-mail: brunaaraujojacob@hotmail.com

\begin{abstract}
Resumo. Mycoplasma hyopneumoniae é o patógeno primário da patologia conhecida como pneumonia enzoótica, uma doença respiratória crônica altamente contagiosa que acomente suínos, caracterizada por alta morbidade e baixa mortalidade. O agente etiológico se encontra na mucosa respiratória, aderido ao epitélio ciliado da traquéia, brônquios e bronquíolos. As infecções ocorrem em todo o mundo e causam grandes impactos econômicos para a indústria de suínos. O presente trabalho teve objetivo realizar uma revisão sobre as estratégias de controle e prejuízos econômicos causados pelo $M$. hyopneumoniae, para isso foi realizadas pesquisas baseadas em informações adquiridas de artigos científicos, livros, teses e dissertações sobre o M. hyopneumoniae. A transmissão do agente ocorre principalmente pelo contato direto das secreções respiratórias de um suíno portador com os suscetíveis. A doença é mais observada nos animais em crescimento e terminação. Após a infecção ocorre destruição do aparelho mucociliar, juntamente com a alteração da resposta imune, aumenta a suscetibilidade de suínos afetados a infecções secundárias. Os sinais clínicos se baseiam em tosse seca, corrimento nasal, baixo desenvolvimento de rebanho, pelo sem brilho e desuniformidade de escore entre leitões. A gravidade das lesões depende de fatores ambientais, manejo e imunidade do hospedeiro. Existem vários testes de diagnóstico que podem detectar o agente, a escolha do teste depende das circunstâncias clínicas do paciente e da propriedade, sendo os mais utilizados o teste de Reação de polimerase em cadeia (PCR) e ELISA. A vacinação é comumente utilizada, estudos observam redução de cargas bacterianas e queda na gravidade dos sinais clínicos em suínos vacinados, atualmente as vacinas disponíveis são econômicas e de fácil acesso, mas alguns estudos concluíram que nem a vacinação nem medicação preventiva podem impedir que a infecção e adesão de $M$. hyopneumoniae às células ciliadas do trato respiratório ocorra. são necessárias pesquisas visando melhorar a compreensão dos mecanismos de ação do microrganismo e da interação do mesmo com o hospedeiro e com outros patógenos, pois essas pesquisas podem auxiliar no desenvolvimento e aprimoramento de métodos de controle, como o desenvolvimento de novas vacinas que conferem melhor proteção ao animal.
\end{abstract}

Palavras-chave: Doenças bacterianas, pneumonia enzoótica, micoplasmose

\section{Mycoplasma hyopneumoniae in swine: Review}
Abstract. Mycoplasma hyopneumoniae is the primary pathogen of the pathology known as enzootic pneumonia, a highly contagious chronic respiratory disease that affects pigs, characterized by high morbidity and low mortality. The etiologic agent is found in the respiratory mucosa, adhered to the ciliated epithelium of the trachea, bronchi and bronchioles. Infections occur worldwide and have major economic impacts for the pig industry. The present work aimed to carry out a review of the control strategies and economic losses caused by M. hyopneumoniae, for this purpose research was carried out 
based on information acquired from scientific articles, books, theses and dissertations on $M$. hyopneumoniae. The transmission of the agent occurs mainly by direct contact of the respiratory secretions of a pig with a susceptible pig. The disease is most commonly seen in growing and finishing animals. After the infection, destruction of the mucociliary system occurs, together with the alteration of the immune response, increases the susceptibility of pigs affected to secondary infections. Clinical signs are based on dry cough, runny nose, low herd development, lack of shine and uneven score among piglets. The severity of the lesions depends on environmental factors, management and host immunity. There are several diagnostic tests that can detect the agent, the choice of the test depends on the patient's clinical circumstances and property, the most used being the Polymerase Chain Reaction (PCR) and ELISA tests. Vaccination is commonly used, studies have observed a reduction in bacterial loads and a drop in the severity of clinical signs in vaccinated pigs, currently available vaccines are economical and easy to access, but some studies have concluded that neither vaccination nor preventive medication can prevent infection and adhesion of M. hyopneumoniae to the hair cells of the respiratory tract to occur. research is needed to improve understanding of the microorganism's mechanisms of action and its interaction with the host and other pathogens, as this research can assist in the development and improvement of control methods, such as the development of new vaccines that provide better protection to the animal.

Keywords: Bacterial diseases, enzootic pneumonia, mycoplasmosis

\section{Introdução}

A suinocultura é uma importante atividade no agronegócio de diversos países, incluindo o Brasil, no segundo trimestre de 2020 o abate de suínos cresceu significativamente, tanto na comparação com o primeiro trimestre de 2020 quanto em comparação contra o segundo trimestre de 2019. Em 2021 as exportações totais de carne suína, chegaram a um volume embarcado de 63,1 mil toneladas, número $7,8 \%$ menor em relação ao mesmo período de 2020, com 68,5 mil toneladas (ABIEC, 2021).

Para que a produção tenha eficiência torna-se necessário o controle de diferentes enfermidades, havendo por consequência uma menor interferência na saúde do suíno (ㅌin, 2015). Neste contexto, a bactéria Mycoplasma hyopneumoniae causadora da Pneumonia Enzoótica suína, é relatada como um dos principais agentes envolvidos no complexo de doenças respiratórias suínas e responsável por consideráveis perdas econômicas na produção de suínos (Liu et al., 2019). A infecção pelo Mycoplasma inicia com a colonização do epitélio respiratório, provoca uma perda de depuração mucociliar, resposta inflamatória, imunossupressão do hospedeiro e predispõe os suínos a infecções secundárias com bactérias incluindo Pasteurella multocida, Actinobacillus pleuropneumoniae e Streptococcus sui (Liu et al., 2019).

A pneumonia causada por Mycoplasma hyopneumoniae está presente em todos os países onde a suinocultura exerce importância. No Brasil, estima-se que 95\% das granjas comerciais sejam positivas para M. hyopneumoniae. As exceções tendem a ser as granjas núcleo, onde a eliminação do agente ocorre com maior frequência devido ao controle sanitário e medidas de biossegurança (Takeuti \& Barcellos, 2017). A longa persistência da bactéria no trato respiratório do suíno dificulta a realização de programas de erradicação em granjas comerciais (Takeuti \& Barcellos, 2017).

Práticas inadequadas de manejo como superlotação nas baias, excesso de poeira, gases tóxicos, excessos de temperatura, umidade inadequadas e ausência de vazio sanitário são fatores de risco para a ocorrência de pneumonias. Ainda, a mistura de leitões de diferentes origens nos povoamentos de creches e terminações, frequente em granjas brasileiras, poderia favorecer a disseminação de variantes de $M$. hyopneumoniae e a consequente ocorrência de pneumonia na fase de terminação (Takeuti \& Barcellos, 2017).

O controle de infecções causadas por Mycoplasma em rebanhos suínos pode ser realizado de várias formas, as condições de habitação devem otimizar o rebanho, estão relacionados a estratégias para prevenir fatores que podem desestabilizar a imunidade desses animais (Pieters et al., 2009).

O M. hyopneumoniae, é um agente que escapa das defesas naturais do hospedeiro fixando-se firmemente à sua mucosa respiratória e posterior aderência ao epitélio das vias aéreas, reduzindo a 
capacidade funcional do sistema muco-ciliar, aumentando o acúmulo de células e a susceptibilidade para o avanço da bactéria por brônquios e bronquíolos, causando o agravamento do quadro clínico e queda nos mecanismos de defesa do animal (Hein, 2015).

O presente trabalho tem como objetivo realizar uma revisão de literatura sobre dificuldades no controle e prejuízos causados pelo Mycoplasma hyopneumoniae. A revisão está baseada em informações adquiridas de artigos científicos encontrados nas bases de indexadoras: Scielo, Science direct, google acadêmico, além de livros de microbiologia veterinária, teses e dissertações relacionadas com o agente etiológico Mycoplasma hyopneumoniae.

\section{Características do agente}

Mycoplasma hyopneumoniae é um agente espécie-específico pertencente à Família Mycoplasmataceae da Classe Mollicutes e Filo Firmicutes, o agente não possui parede celular, o que o torna bastante pleomórfico. É o agente primário da pneumonia enzoótica e do complexo respiratório dos suínos, um dos patógenos respiratórios economicamente mais relevantes no mundo, cuja infecção é conhecida por apresentar tosse não produtiva, redução no crescimento e piora da conversão alimentar. Em 1965 o procarioto foi isolado pela primeira por Mare e Switzer e posteriormente, Goodwin et al. (1968) isolaram e reproduziram a pneumonia enzoótica experimentalmente, confirmando a espécie como agente etiológico da doença (Andrade, 2018).

M. hyopneumoniae possui um metabolismo limitado e poucas vias biossintéticas, a ausência de algumas vias biossintéticas implica no fato de que a bactéria precisa obter aminoácidos, purinas, pirimidinas e componentes da membrana celular do ambiente de crescimento, fazendo com que o requerimento nutricional seja complexo. Esse fenômeno explica uma grande dificuldade do cultivo in vitro da bactéria que apresenta crescimento fastidioso entre 4 e 8 semanas, precisando de um meio altamente nutritivo e ser incubado a $37^{\circ} \mathrm{C}$ (Deeney et al., 2019) em meios de cultura laboratoriais, necessitando de um $\mathrm{pH}$ entre 7,2 e 7,8 e meios específicos para que ocorra crescimento efetivo (GautierBouchardon, 2018; Simionatto et al., 2013).

A falta de parede celular faz com que os antimicrobianos que agem diretamente nesta estrutura ou na sua formação sejam ineficazes no controle dos micoplasmas, levando a ser necessário então o emprego de produtos que interfiram na síntese proteica ou dos ácidos nucleicos da bactéria. Esta característica colabora para o controle do M. hyopneumoniae no ambiente de criação, já que são organismos extremamente susceptíveis ao calor, detergentes e desinfetantes, como o quaternário de amônia (Andrade, 2018).

\section{Sinais clínicos}

Embora todos os suínos sejam susceptíveis, as fases de recria e terminação são as mais propensas a apresentarem os sinais característicos (Sibila et al., 2009), devido ao fato desses animais apresentarem baixa imunidade contra o agente em questão (Cassiano, 2015). Após a contaminação o aparecimento dos sinais clínicos ocorre aproximadamente após 13 dias, variando entre seis e 27 dias (Şrensen et al., 1997). A tosse crônica não produtiva, é o principal sinal clínico da patogenia, aparece de 10 a 16 dias após a infecção experimental, podendo variar muito em condições de campo. Lesões macroscópicas, consistindo de áreas roxas a cinzas de consolidação pulmonar, são encontradas principalmente bilateralmente nas partes apical, cardíaca, intermediária e anterior dos lobos diafragmáticos (Maes et al., $\underline{2008)}$.

Macroscopicamente são identificadas lesões pneumônicas na porção crânio-ventral do pulmão, principalmente nos lobos apical, cardíaco, intermediário e diafragmático (Sobestiansky et al., 1999). Caracterizadas por áreas de consolidação pulmonar denominadas de lesões tipo hepatização e coloração podendo variar entre púrpura e cinza (Sibila et al., 2009; Sobestiansky et al., 1999; Thacker, 2004).

As lesões microscópicas da Pneumonia Enzootica variam de acordo com o progresso da doença, como descrito por Sibila et al. (2009), Sobestiansky et al. (1999) e Thacker (2004). Inicialmente ocorre uma proliferação linfoide podendo se estender até a camada muscular da submucosa dos bronquíolos para logo ocorrer uma infiltração de linfócitos e monócitos nas regiões próximas aos brônquios, 
bronquíolos e vasos pulmonares. Com o agravamento da doença ocorre espessamento da parede alveolar e hiperplasia dos folículos linfoides com estenose das vias aéreas (트, 2015).

\section{Patogenia}

A infecção pelo M. hyopneumoniae se inicia com sua entrada pelo trato respiratório suíno e posterior aderência ao epitélio das vias aéreas, fato dependente da concentração de cílios no local e do número de micoplasmas presentes (Sibila et al., 2009). A viabilidade da bactéria não interfere em sua capacidade de adesão, sendo descrito que mesmo que se apresente lisada, esta tem maior atividade aderente que micoplasmas intactos (Sibila et al., 2009). Com o progresso da infecção há perda dos cílios e morte celular (Blanchard et al., 1992; DeBey \& Ross, 1994; Jacques et al., 1992).

Devido a redução da capacidade funcional do sistema muco-ciliar há diminuição da limpeza das vias aéreas, aumentando o acúmulo de células e a susceptibilidade a patógenos secundários, além de auxiliar para o avanço da bactéria agir por brônquios e bronquíolos, causando assim o agravamento do quadro clínico e imunossupressão do animal, já que o microrganismo consegue alterar o tamanho e expressão das lipoproteínas da membrana celular para possibilitar a evasão pelo sistema imune (Hein, 2015).

A infecção faz com que macrófagos e linfócitos aumentem a produção de citocinas pró-inflamatórias (interleucinas e TNF) no tecido linfoide associado aos brônquios (BALT), que resultam em uma intensa infiltração de células mononucleares na região peribrônquica e perivascular (Hein, 2015).

\section{Epidemiologia}

As doenças respiratórias suínas se manifestam como uma síndrome denominada "Complexo Doença Respiratória dos Suínos" (PRDC), por resultarem da combinação de dois ou mais agentes infecciosos e fatores de risco presentes nos sistemas criatórios (EMBRAPA 2013). O M. hyopneumoniae é um agente que está presente no complexo de doenças respiratórias dos suínos e abre portas para diferentes microrganismos atuarem na infecção.

A doença apresenta uma elevada morbidade, que capacita acometer vários suínos rapidamente, e apresenta baixa mortalidade. Possui características brandas, porém podem resultar sérios problemas se associados a infecções secundárias (Hein, 2015). Devido a destruição do epitélio ciliar do trato respiratório e com o acúmulo de secreções inflamatórias, além de debris celulares existe a predisposição do animal às infecções secundárias (Sobestiansky et al., 1999).

Os suínos nascem livres de M. hyopneumoniae; porém, assim como outros patógenos respiratórios, a bactéria é transmitida através da inalação de gotículas expelidas durante a tosse de animais infectados

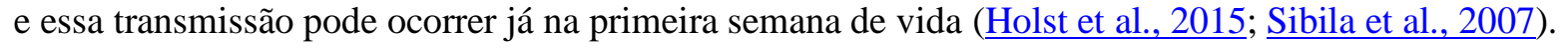

Em um estudo realizado por Miranda Morales et al. (2020) foi feita a detecção de anticorpos para $M$. hyopneumoniae utilizando o teste ELISA, coletaram amostras de soro de suínos encontrados em granjas no estado de São Paulo, coletaram amostras de matrizes, leitões antes do processo de desmame e suínos em fase de terminação. De 150 amostras testadas, 90 (60\%) apresentaram soropositividade para $M$. hyopneumoniae.

O contato direto é a principal forma de disseminação do agente, a presença de um único suíno infectado em uma população virgem dissemina a patologia dentro da propriedade (Betlach et al., 2021). Embora o contato direto seja a principal via de transmissão do agente, existem trabalhos que consideram o risco de um rebanho ser infectado ser inversamente proporcional à proximidade com outras granjas vizinhas (Goodwin, 1985; Zhuang et al., 2002). Alguns estudos exploram a capacidade da bactéria ser transmitida pelo ar. O M. hyopneumoniae pode ser carreado via aerógena e percorrer até $9,2 \mathrm{~km}$ de distância. No intuito de testar a hipóteses recolheram amostras de ar de diferentes direções e distâncias a partir de uma granja infectada, totalizando 31 pontos de amostragem. Em conclusão o agente foi detectado em seis pontos de coleta até a distância de $9,2 \mathrm{~km}$ do foco, das quais em três amostras o agente encontrava-se viável após inoculação intra-traqueal, induzindo sinais clínicos e lesões pulmonares. Outra forma de difusão da infecção é com a aquisição de fêmeas nulíparas oriundas de planteis onde não existe a ocorrência da patologia, dessa forma as fêmeas irão parir filhotes que não receberam anticorpos contra a bactéria no colostro, causando assim o aumento do índice de infecção (타, 2015). 


\section{Diagnóstico}

O diagnóstico das infecções causadas pelo $M$. hyopneumoniae pode ser realizado por uma variedade de abordagens clinicas, incluindo, observação das lesões de abate, acompanhamento nos lotes, cultura bacteriológica, ensaio imunoenzimático e inspeção post mortem (Vangroenweghe et al., 2015). O isolamento bacteriológico é o "padrão-ouro" para a detecção do agente, porém, é uma técnica laboriosa e raramente utilizada já que o microrganismo apresenta um crescimento fastidioso e demorado, necessitando de meios específicos e caros para seu crescimento (Hein et al., 2015). Os principais materiais utilizados para isolamento são exsudato traqueal, aspirados e tecido retirado do bordo do pulmão lesionado.

O teste de reação em cadeia da polimerase (PCR) é visto como a ferramenta mais sensível para detectar a infecção, devido a sua alta sensibilidade necessitam de uma pequena quantidade do agente para a detecção (Calsamiglia \& Pijoan, 2000; Pepovich et al., 2017). Este método permite o diagnóstico do agente tanto em animais vivos como em mortos, através de amostras a partir de lavado broncoalveolar, suabes nasal e traqueo-bronquial (Baumeister et al., 1998; Sibila et al., 2009; Sørensen et al., 1997). O organismo pode ser detectado por teste de imunofluorescência, mas este teste tem sensibilidade limitada. A sorologia pode ser usada para mostrar a presença do organismo em um rebanho, mas não é adequada para o diagnóstico em animais individuais (Sørensen et al., 1997).

A avaliação de lesões pulmonares no abatedouro é uma forma de diagnóstico comumente usada para estimar a prevalência e severidade da doença nas granjas, essa avaliação permite identificar a sanidade do rebanho por meio das lesões pulmonares. Além disso, é utilizado o escore em abatedouros e pode ser útil para detectar doença subclínica no rebanho. Deve-se ressaltar; porém, que a determinação do escore de pneumonias ao abate apresenta certa subjetividade. A dinâmica de infecção é variável (Andrade, $\underline{2018}$.

\section{Profilaxia e controle}

Nas práticas de manejo e instalações buscamos formas de minimizar a disseminação do agente entre os animais, o emprego do sistema "todos dentro, todos fora" é uma conhecida forma de interromper o curso de infecções nas granja, visto que um grupo de animais entram e sai de uma instalação ao mesmo tempo, havendo igualdade na exposição aos agentes. Uma ventilação adequada obtida no manejo de cortinas das instalações permitem uma menor pressão de infecção no local de criação (Hein, 2015).

A infecção por $M$. hyopneumoniae causa alta taxa de morbidade e perda econômica em suínos estoque. São necessárias medidas oportunas e adequadas para controlar esta doença, que impeçam ou minimizem o acometimento dos animais alojados (Manev, 2018). Assim, a instituição de programas de biossegurança nas granjas produtoras de suínos torna- se uma forma eficaz de controle de infecções por M. hyopneumoniae podem ser realizados por meio da otimização das condições de manejo, moradia e pela vacinação (Maes et al., 2020).

As empresas de genética precisam vender os animais livres, quando ocorre entrada do agente dentro da propriedade, é necessário utilizar o controle rígido do $M$. hyopenumoniae, utilizando práticas de cesariana, desmame hiperprecoce, desmame medicado, que se baseiam em forçar uma desmama com cerca de nove dias de vida do animal, utilizando alta dosagem antimicrobiana, para segregar os leitões e retirar o microrganismo da propriedade, para assim tentar lucrar na venda de fêmeas livres, ainda que ocorra influência no desempenho dos leitões pós desmame (Tamiozzo et al., 2011).

Existem vários procedimentos e políticas, que buscam melhorar o controle da saúde do rebanho (Hein et al., 2015). Todavia, estratégias de vacinação, redução de fatores estresseantes, estratégias modernas de fazenda são necessárias e úteis, mas mesmo o manejo mais cuidadoso não é capaz de proteger o rebanho de Infecções bacterianas.

\section{Biosseguridade}

Programas de biosseguridade nas granjas de suínos são eficazes para diminuir a disseminação do agente, buscam reduzir a introdução, disseminação e o contato com agentes infecciosos em um sistema de criação, um programa de biossegurança pode ser dividido em externo e interno, de acordo com os 
objetivos e as medidas aplicáveis em cada um. Os componentes externos envolvem todas as práticas que buscam impedir a entrada de novos agentes patogênicos no ambiente de criação, é muito difícil realizar experimentos de biosseguridade externa. A maior parte do conhecimento existente atualmente é relativa a princípios básicos com rotas de eliminação e transmissão dos agentes, hospedeiros susceptíveis, sobrevivência dos agentes fora do hospedeiro, portadores sadios e dose infectante (Souza et al., 2021). Já os internos estão associadas ao adequado programa de vacinação e controle de fatores de riscos, são fundamentais para reduzir a disseminação dos patógenos entre diferentes salas num mesmo rebanho e ter controle efetivo de enfermidades, cujos agentes geralmente estão presentes nos rebanhoslimitar a disseminação e expressão de agentes patogênicos que já estejam presentes no rebanho (Souza et al., 2021).

Como alternativa também se constitui o plantio de árvores no entorno da área, para a formação de um cinturão verde que servirá como barreira física contra a transmissão de agentes por aerossóis e limitações a respeito da entrada de pessoas, equipamentos e animais na área interna da granja. Entretanto, de todas as alternativas de biossegurança, o fator que se torna mais importante na transmissão e disseminação de patógenos dentro da granja suína é a aquisição de animais infectados para a reposição, o animal novo na granja deve passar pelo período de quarentena para adaptação da microbiota do animal ao novo ambiente (Betlach et al., 2021).

\section{Tratamento com antimicrobianos}

A terapia e a metafilaxia para doenças geralmente são conduzidas pela adição de medicamentos na forragem ou na água, assim facilita a aplicação e diminui o estresse do animal. Administrar medicamentos na forragem é útil em casos de enzoótica e doenças crônicas como pneumonia enzoótica suína. Porém com o surgimento de múltiplas resistências antimicrobianas a aplicação de antimicrobianos é feita somente se necessário e o medicamento concreto é escolhido cautelosamente (Manev, 2018).

Os animais infectados podem ser tratados por meios de medicamentos antimicrobianos ativos contra o Mycoplasma hyopneumoniae (Maes et al., 2020). Considerando o fato de que M. hyopneumoniae carece de uma parede celular, isso o torna resistente a todos os antibióticos betalactamase, alguns macrolídeos de 14 membros, como eritromicina e oleandomicina e tetraciclinas. Porém, embora $M$. hyopneumoniae mostre resistência adquirida às tetraciclinas, macrolídeos de 16 membros (tilosina, tilmicosina), lincosamidas (lincomicina) e fluoroquinolonas (Maes et al., 2020) estão em uso no tratamento da Pneumonia Enzootica suína.

O grupo de antimicrobianoss potencialmente ativos contra $M$. hyopneumoniae inclui tetraciclinas, macrolídeos, lincosamidas, pleuromutilinas, fluorquinolonas, anfenicóis e aminoglicosídeos (Pepovich et al., 2015), sendo as tetraciclinas e macrolídeos os mais frequentemente utilizados para tratamento e controle de infecções respiratórias (Timmerman et al., 2006). A decisão de medicar deve ser analisada cuidadosamente, já que os antimicrobianos podem não ser capazes de prevenir a infecção ou erradicar a bactéria do trato respiratório, podendo levar a um quadro de resistência microbiana desnecessária (Maes et al., 2020).

\section{Vacinação}

A vacinação é comumente utilizada, uma vez que foi demonstrada redução nas cargas bacterianas e gravidade clínica em porcos vacinados (Betlach et al., 2021), a imunoprofilaxia contra pneumonia enzoótica suína conta com a investigação de diferentes esquemas de vacinação. Alguns autores utilizam de vacinas inativadas (Martelli et al., 2014); enquanto outros preferem utilizar as vacinas vivas atenuadas (Feng et al., 2013). A aplicação de vacinas elaboradas com culturas inativas de microrganismos é uma prática rotineira nos rebanhos industriais. Essa aplicação pode ser feita em leitões, podendo ainda ser realizada em matrizes como forma de reduzir a transmissão do agente à prole, além de aumentar os níveis de anticorpos no colostro das fêmeas (Hein, 2015). Um estudo realizado por Hein 2015, buscou verificar a influência da imunidade materna na resposta à imunização de leitões contra $M$. hyopneumoniae, onde acompanharam suínos desde seu nascimento até o momento do abate, vacinaram um grupo de 29 matrizes para efeito de comparação de níveis de anticorpos, colheram soro sanguíneo das matrizes no período pre parto, seguida de uma colheita no dia de parto, ainda no dia do parto foi feita a colheita de sangue de dois de seus leitões que receberam marcação individual na orelha, 
propiciando uma nova colheita do sangue após três dias do nascimento, para verificar a relação entre ingestão de colostro das fêmeas e o nível de anticorpos adquirido pelos leitões. Após os leitões ingerirem o colostro, observaram que os animais do grupo de matrizes que receberam a vacina apresentaram níveis de anticorpos anti- $M$. hyopneumoniae, linfócitos TCD4, linfócitos B e macrófagos, superiores em comparação aos leitões provenientes de matrizes não vacinadas. Concluindo que as matrizes suínas conferem imunidade humoral contra o Mycoplasma hyopneumoniae para os leitões a partir da ingestão do colostro.

O esquema de vacinação é escolhido de forma a atender o tipo de rebanho e o sistema de produção. Vacinas de aplicação de uma dose podem ser administradas com 3 semanas de idade e leva a um maior crescimento médio diário, menor conversão de forragem, menor aparecimento de lesões pulmonares e diminuição nos indices de mortalidade (Pepovich et al., 2015). Um estudo realizado por Michiels et al. (2017), testou a eficácia da vacinação em suínos com cepas de M. hyopneumoniae altamente virulenta, os porcos que receberam a vacina apresentaram significativamente menos tosse e menos lesões pulmonares em comparação com os suínos não vacinados, na necropsia dos animais, os animais que foram vacinados também apresentaram menor quantidade de DNA de $M$. hyopneumoniae no lavado bronco-alveolar. Concluindo assim, que embora a colonização não seja evitada com a vacina, ela reduz os sinais clínicos, lesões pulmonares e melhora o desempenho dos animais.

\section{Considerações finais}

M. hyopneumoniae é um patógeno muito importante na suinocultura, ocasiona grandes perdas para a indústria suína. O controle da pneumonia enzoótica pode ser realizado por meio das práticas de manejo, condições de moradia, medicamentos e vacinação. Todavia, essas medidas ajudarão a diminuir o nível de infecção no rebanho e melhorar as condições de saúde dos animais, mas essas práticas não garantem a ausência do patógeno no rebanho.

Pesquisas tem se concentrado em novas tecnicas baseadas na epidemiologia e transmissão em diferentes sistemas de produção. Entretanto são necessárias pesquisas visando melhorar a compreensão dos mecanismos de ação do microrganismo e da interação do mesmo com o hospedeiro e com outros patógenos, pois essas pesquisas podem auxiliar no desenvolvimento e aprimoramento de métodos de controle, como o desenvolvimento de novas vacinas que conferem melhor proteção ao animal.

\section{Referências bibliográficas}

ABIEC. (2021). Associação Brasileira das Indústrias Exportadoras de Carnes. Exportações Brasileiras de Carne Bovina - Brazilian Beef Exports (P. e A. Ministério da Agricultura (ed.)). Governo brasileiro.

Andrade, M. R. (2018). Patógenos Respiratórios dos Suínos: Diversidade genética de 15 Mycoplasma hyopneumoniae em Minas Gerais e dinâmica de 16 colonização e resposta imune por Haemophilus parasuis.

Baumeister, A. K., Runge, M., Ganter, M., Feenstra, A. A., Delbeck, F., \& Kirchhoff, H. (1998). Detection of Mycoplasma hyopneumoniae in bronchoalveolar lavage fluids of pigs by PCR. Journal of Clinical Microbiology, 36(7), 1984-1988.

Betlach, A. M., Fano, E., VanderWaal, K., \& Pieters, M. (2021). Effect of multiple vaccinations on transmission and degree of Mycoplasma hyopneumoniae infection in gilts. Vaccine, 39(4), 767-774.

Blanchard, B., Vena, M. M., Cavalier, A., Le Lannic, J., Gouranton, J., \& Kobisch, M. (1992). Electron microscopic observation of the respiratory tract of SPF piglets inoculated with Mycoplasma hyopneumoniae. Veterinary Microbiology, 30(4), 329-341.

Calsamiglia, M., \& Pijoan, C. (2000). Colonisation state and colostral immunity to Mycoplasma hyopneumoniae of different parity sows. The Veterinary Record, 146(18), 530-532.

Cassiano, L. L. (2015). Implementação de técnicas moleculares e microscopia eletrônica de transmissão para pesquisa de Mycoplasma hyopneumoniae em suínos.

DeBey, M. C., \& Ross, R. F. (1994). Ciliostasis and loss of cilia induced by Mycoplasma hyopneumoniae in porcine tracheal organ cultures. Infection and Immunity, 62(12), 5312-5318. 
Deeney, A. S., Maglennon, G. A., Chapat, L., Crussard, S., Jolivet, E., \& Rycroft, A. N. (2019). Mycoplasma hyopneumoniae evades phagocytic uptake by porcine alveolar macrophages in vitro. Veterinary Research, 50(1), 1-15. https://doi.org/10.1186/s13567-019-0667-6.

EMBRAPA - Empresa Brasileira de Pesquisa Agropecuária. (2013). Suinos e Aves.

Feng, Z.-X., Wei, Y.-N., Li, G.-L., Lu, X.-M., Wan, X.-F., Pharr, G. T., Wang, Z.-W., Kong, M., Gan, Y., \& Bai, F.-F. (2013). Development and validation of an attenuated Mycoplasma hyopneumoniae aerosol vaccine. Veterinary Microbiology, 167(3-4), 417-424.

Gautier-Bouchardon, A. V. (2018). Antimicrobial resistance in Mycoplasma spp. Microbiology Spectrum, 6(4), 4-6. https://doi.org/10.1128/microbiolspec.arba-0030-2018.

Goodwin, R.F.W. (1985). Apparent reinfection of enzooticpneumonia-free pig herds: search for possible causes. Veterinary Record, 77, 690-694.

Goodwin, R.F.W., Pomeroy, A.P. \& Whittlestone, P. (1968). Production of enzootic pneumoniae in pigs with a mycoplasma. Veterinary Record, 77, 1247-1249.

Hein, H. E. (2015). Influência da imunidade de matrizes suínas na resposta à vacinação de leitões contra Mycoplasma hyopneumoniae. Universidade Federal do Rio Grande do Sul.

Holst, S., Yeske, P., \& Pieters, M. (2015). Elimination of Mycoplasma hyopneumoniae from breed-towean farms: A review of current protocols with emphasis on herd closure and medication. Journal of Swine Health and Production, 23(6), 321-330.

Jacques, M., Blanchard, B., Foiry, B., Girard, C., \& Kobisch, M. (1992). In vitro colonization of porcine trachea by Mycoplasma hyopneumoniae. Annales de Recherches Vétérinaires, 23(3), 239-247.

Liu, L., Li, R., Zhang, R., Wang, J., An, Q., Han, Q., Wang, J., \& Yuan, W. (2019). Rapid and sensitive detection of Mycoplasma hyopneumoniae by recombinase polymerase amplification assay. Journal of Microbiological Methods, 159, 56-61. https://doi.org/10.1016/j.mimet.2019.02.015.

Maes, D., Boyen, F., Haesebrouck, F., \& Gautier-Bouchardon, A. V. (2020). Antimicrobial treatment of Mycoplasma hyopneumoniae infections. The Veterinary Journal, 259, 105474.

Maes, D., Segales, J., Meyns, T., Sibila, M., Pieters, M., \& Haesebrouck, F. (2008). Control of Mycoplasma hyopneumoniae infections in pigs. Veterinary Microbiology, 126(4), 297-309. https://doi.org/10.1016/j.vetmic.2007.09.008.

Manev, I. (2018). Mycoplasma hyopneumoniae infections in pigs-measures for control. Tradition and Modernity in Veterinary Medicine, 2(5), 9-14.

Martelli, P., Saleri, R., Cavalli, V., De Angelis, E., Ferrari, L., Benetti, M., Ferrarini, G., Merialdi, G., \& Borghetti, P. (2014). Systemic and local immune response in pigs intradermally and intramuscularly injected with inactivated Mycoplasma hyopneumoniae vaccines. Veterinary Microbiology, 168(2-4), 357-364.

Michiels, A., Arsenakis, I., Boyen, F., Krejci, R., Haesebrouck, F., \& Maes, D. (2017). Efficacy of one dose vaccination against experimental infection with two Mycoplasma hyopneumoniae strains. BMC Veterinary Research, 13(1), 1-10.

Miranda Morales, R. E., Rojas Trejo, V., López-Cerino, L. E., Carrillo Casas, E. M., Sarmiento Silva, R. E., Trujillo Ortega, M. E., Beltrán Figueroa, R., \& Trigo Tavera, F. J. (2020). Frecuencia de $M$. hyopneumoniae, M. hyorhinis y M. hyosynoviae en muestras nasales y de pulmón de cerdos con síntomas de neumonía enzoótica porcina. Revista Mexicana de Ciencias Pecuarias, 11(4), 946-960.

Pepovich, R, Nikolov, B., Hristov, K., \& Genova, K. (2017). Pathological observation in pigs naturally infected with Mycoplasma hyopneumoniae. Bulgarian Journal of Veterinary Medicine, 20(1), 338344.

Pepovich, Roman, Nikolov, B., Sirakov, I., Genova, K., Hristov, K., Nikolova, E., Hajiolova, R., \& Beltova, B. (2015). Clinical testing of combined vaccine against enzootic pneumonia in industrial pig farming in Bulgaria. Macedonian Veterinary Review, 38(2), 195-201.

Pieters, M., Pijoan, C., Fano, E., \& Dee, S. (2009). An assessment of the duration of Mycoplasma hyopneumoniae infection in an experimentally infected population of pigs. Veterinary Microbiology, 134(3-4), 261-266. https://doi.org/10.1016/j.vetmic.2008.08.016. 
Sibila, M, Nofrarias, M., Lopez-Soria, S., Segales, J., Riera, P., Llopart, D., \& Calsamiglia, M. (2007). Exploratory field study on Mycoplasma hyopneumoniae infection in suckling pigs. Veterinary Microbiology, 121(3-4), 352-356.

Sibila, Marina, Pieters, M., Molitor, T., Maes, D., Haesebrouck, F., \& Segalés, J. (2009). Current perspectives on the diagnosis and epidemiology of Mycoplasma hyopneumoniae infection. The Veterinary Journal, 181(3), 221-231. https://doi.org/10.1016/j.tvj1.2008.02.020.

Simionatto, S., Marchioro, S. B., Maes, D., \& Dellagostin, O. A. (2013). Mycoplasma hyopneumoniae: from disease to vaccine development. Veterinary Microbiology, 165(3-4), 234-242. https://doi.org/10.1016/j.vetmic.2013.04.019.

Sobestiansky, J., Barcellos, D., Moraes, N., Carvalho, L. F., \& Oliveira, S. (1999). Clinica e patologia suína. Universidade Federal de Goiáas.

Sørensen, V., Ahrens, P., Barfod, K., Feenstra, A. A., Feld, N. C., Friis, N. F., Bille-Hansen, V., Jensen, N. E., \& Pedersen, M. W. (1997). Mycoplasma hyopneumoniae infection in pigs: duration of the disease and evaluation of four diagnostic assays. Veterinary Microbiology, 54(1), 23-34. https://doi.org/10.1016/S0378-1135(96)01266-7.

Souza, T. C. G. D., Silva, V. S., Mores, M. A. Z., Kramer, B., Leme, R. A., Porto, G. S., \& Alfieri, A. A. (2021). Mycoplasma hyopneumoniae in free-living wild boars in Paraná, Brazil. Brazilian Journal of Microbiology, 1-7.

Takeuti, K. L., \& Barcellos, D. E. S. N. (2017). O que há de novo sobre a infecção por Mycoplasma hyopneumoniae em suínos. Avanços Em Sanidade, Produção e Reprodução de Suínos II, 53, 6.

Tamiozzo, P. J., Pelliza, B. R., Carranza, A. I., \& Ambrogi, A. (2011). Monitoramento da presença de Mycoplasma hyopneumoniae em granjas de suínos durante a implementação de programas de erradicação. Ciência Rural, 41(4), 699-705.

Thacker, E. L. (2004). Diagnosis of Mycoplasma hyopneumoniae. Animal Health Research Reviews, 5(2), 317-320.

Timmerman, T., Dewulf, J., Catry, B., Feyen, B., Opsomer, G., de Kruif, A., \& Maes, D. (2006). Quantification and evaluation of antimicrobial drug use in group treatments for fattening pigs in Belgium. Preventive Veterinary Medicine, 74(4), 251-263.

Vangroenweghe, F., Labarque, G. G., Piepers, S., Strutzberg-Minder, K., \& Maes, D. (2015). Mycoplasma hyopneumoniae infections in peri-weaned and post-weaned pigs in Belgium and The Netherlands: Prevalence and associations with climatic conditions. The Veterinary Journal, 205(1), 93-97.

Zhuang, Q., Wachmann, H., Mortensen, S., \& Barford, K. (2002). Incidence of Actinobacillus pleuropneumoniae serotype 2 and Mycoplasma hyopneumoniae infections in the Danish SPF herds and risk factors for infections. Proceedings of the 17th International Pig Veterinary Society, Ames, Iowa, 228.

Histórico do artigo:

Recebido: 13 de maio de 2021

Aprovado: 29 de junho de 2021
Licenciamento: Este artigo é publicado na modalidade Acesso Aberto sob a licença Creative Commons Atribuição 4.0 (CC-BY 4.0), a qual permite uso irrestrito, distribuição, reprodução em qualquer meio, desde que o autor e a fonte sejam devidamente creditados. 